\title{
Pillar design around mullock-filled stopes in the 3500 Orebody, Mount Isa Mines
}

D Matthews Glencore Mount Isa Mines, Australia

\begin{abstract}
A two-lift stoping strategy was determined to extract ore close to a previously extracted mullock-filled stope leaving as small a pillar as possible. On successful extraction of the stope, the strategy was adopted for the rest of the retreat using the pillar vertical height to thickness ratio to assess pillar stability when other more generic pillar stability assessment methods predicted unstable pillars.

This method has also been applied to the southern 3000 Orebody to justify the extraction of ore previously thought to be sterilised.
\end{abstract}

\section{Introduction}

In 2010, a sequence of three stopes was being designed adjacent to mullock-filled stopes. Due to a number of recent pillar failures elsewhere in the mine an assessment of the stability of the pillars to be left with the mullock-filled stopes was required. The pillar stability methods in current use predicted that the pillars would be unstable; however, similarly sized pillars in the immediate area had remained stable. An alternative method was therefore devised using the pillar vertical height to thickness ratio.

An alternative stoping method was also devised using two-lift stoping to ensure that the pillars had dimensions expected to remain stable.

\section{$2 \quad$ Background}

\subsection{Mount Isa Mines and the $\mathbf{3 5 0 0}$ Orebody}

Glencore's Mount Isa Mines (MIM) is located in North West Queensland (Figure 1). 6.3 Mt of copper ore is mined annually from two underground mines - Enterprise and X41. From this copper concentrate is produced, smelted and transported to the Townsville Copper Refinery to be further refined into copper cathode at $99.995 \%$ pure copper (Chitumbura et al. 2014).

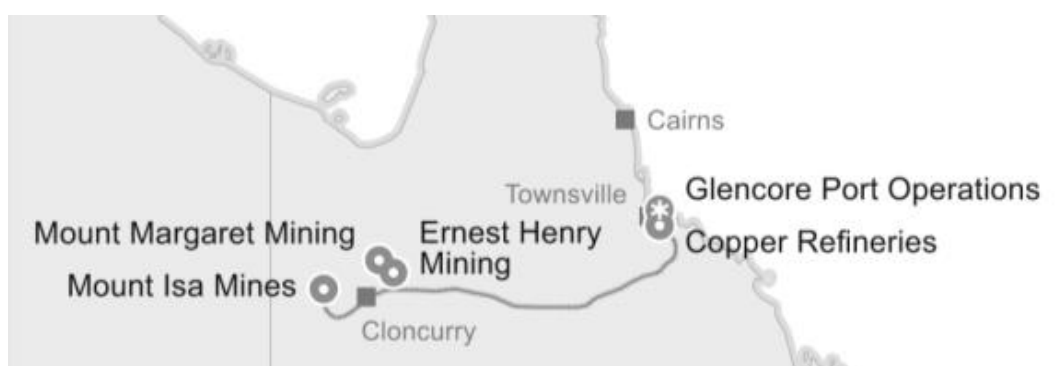

- Copper Operations

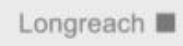
$\circledast$ Port
City / Town
- Rail

Figure 1 MIM location (Chitumbura et al. 2014) 
The Mount Isa Lease is a multi-commodity lease with lead zinc ore being discovered in 1923 and copper, which was discovered in the 1930s, beginning production during the Second World War (Burns 1993). The 3500 Orebody was discovered in 1967 (Burns 1993), with production by sublevel open stoping (SLOS) commencing with U614 stope in 1996 which was subsequently used as a mullock dump for development waste (Chen 2002).

The 3500 Orebody is a continuous north-south striking lens over $1,000 \mathrm{~m}$ in length and dipping between 60 and $70^{\circ}$ to the west; it is approximately $400 \mathrm{~m}$ in height and $60 \mathrm{~m}$ in width (Chen 2002). Stopes were originally approximately $25 \times 25 \mathrm{~m}$ in plan (Chen 2002) but are now usually $40 \times 40 \mathrm{~m}$ in plan and between 150 and $200 \mathrm{~m}$ in height (Figure 2). It extends from $22 \mathrm{C}$ at 2340 reduced level (RL) or 1,107 m depth to 30A which is at $1850 \mathrm{RL}$ or $1597 \mathrm{~m}$ depth.

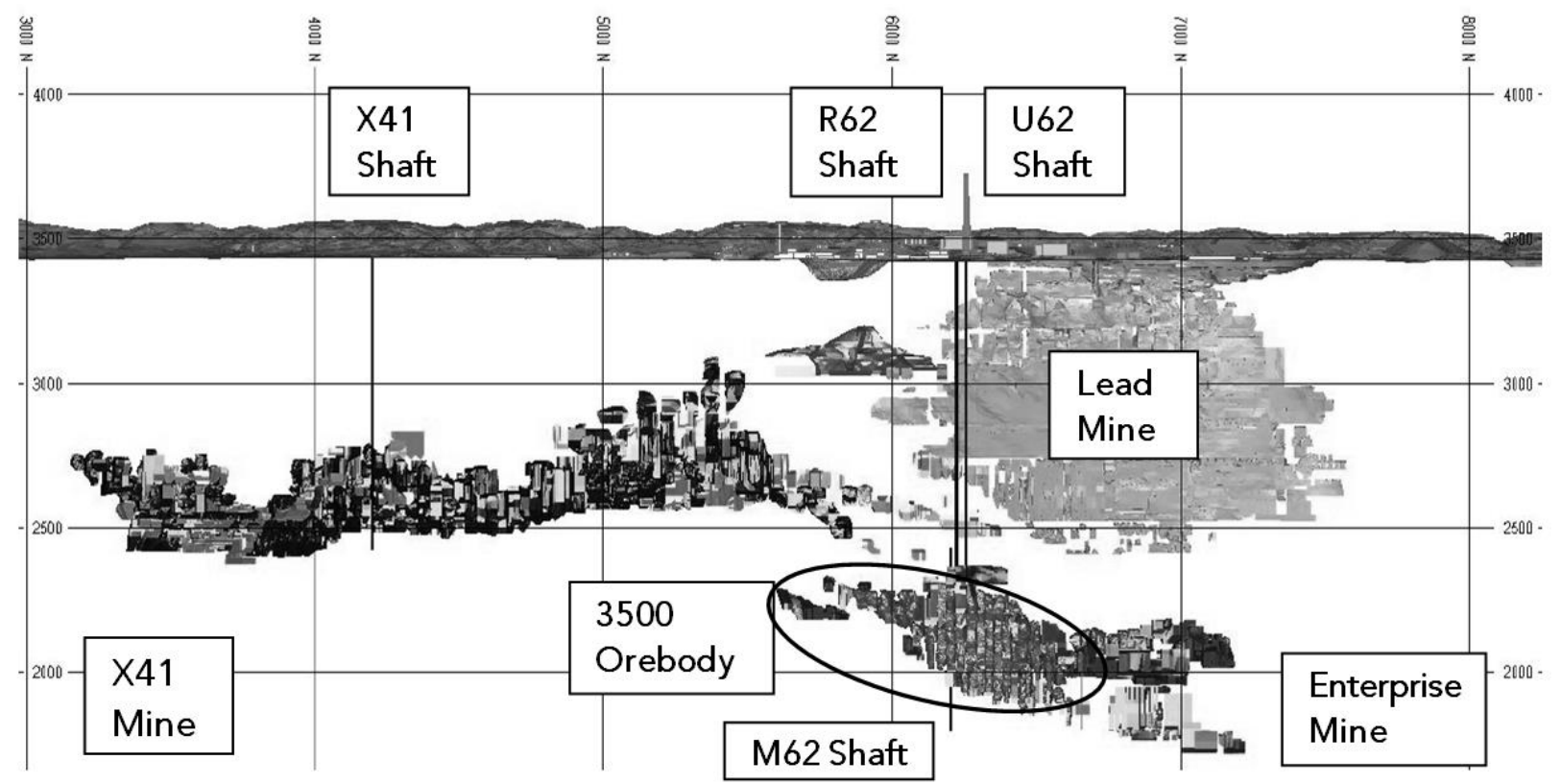

Figure 2 Location of 3500 Orebody within MIM looking west

Ore Haulage was initially by Kiruna electric truck haulage until this was replaced by the M62 internal shaft system in 2000 (Chen 2002). At present ore is mucked to orepasses on a number of sublevels down to 30A where it is tipped to the T63 Crusher. The crushed ore is then conveyed to the M62 internal shaft where it is hoisted to $21 \mathrm{~L}(2360 \mathrm{RL})$ and transferred to the U62 shaft which hoists the ore to surface.

Stopes in the orebody are usually backfilled with paste fill with others being backfilled with cemented hydraulic fill (CHF). If no later stopes adjoin the stope, it is backfilled with hydraulic fill or mullock, which usually comprises development waste.

\subsection{Orebody rock mass}

\subsubsection{Rock properties}

The copper orebodies are located in carbonaceous, dolomitic and pyritic shales of the Proterozoic Urquhart Shale Formation which sit unconformably above the quartzites and greenschists of the Eastern Creek Volcanics (Burns 1993). The rock mass properties for these formations are given in Table 1. Large zones of silica-dolomite alteration occur adjacent to the basement contact zone (BCZ), projecting up into the Urquhart Shales which contain the chalcopyrite mineralisation. 
A Q value of 70 (very good rock mass) was calculated for the orebody rock mass, which comprised the pillars assessed below (Matthews 2011).

Table 1 Summary of 3500 Orebody Rock Properties (MIM 2014)

\begin{tabular}{lccccc}
\hline Formation & $\begin{array}{c}\text { Density } \\
\left(\mathrm{gm} / \mathrm{cm}^{3}\right)\end{array}$ & $\begin{array}{c}\text { Dynamic } \\
\text { modulus } \\
(\mathrm{GPa})\end{array}$ & $\begin{array}{c}\text { Static } \\
\text { modulus } \\
(\mathrm{GPa})\end{array}$ & $\begin{array}{c}\text { Poisson's } \\
\text { Ration }\end{array}$ & $\begin{array}{c}\text { Uniaxial compressive } \\
\text { strength } \\
(\mathrm{MPa})\end{array}$ \\
\hline $\begin{array}{l}\text { Urquhart shale } \\
\text { average }\end{array}$ & 3.06 & 93 & 85 & 0.29 & 210 \\
Breccia average & 2.88 & 85 & 77 & 0.19 & 192 \\
BCZ & 2.68 & 75 & 71 & 0.21 & 140 \\
$\begin{array}{l}\text { Eastern Creek } \\
\text { Volcanics average }\end{array}$ & 2.79 & 83 & 68 & 0.25 & 105 \\
\hline
\end{tabular}

\subsubsection{Major structures}

The 3500 Orebody is terminated down dip by the BCZ which is a sheared and faulted carbonaceous Mylonite of variable thickness and composition which dips to the east (Burns 1993). To the east, the orebody boundary is the footwall (FW) fault which is a 1 to $3 \mathrm{~m}$ wide talc shear with some chalcopyrite mineralisation which dips at approximately $70^{\circ}$ to the west (MIM 2014).

Two other fault sets intersect the orebody, the NNE-SSW, west dipping NS faults and the NNW-SSE striking, near vertical NNW faults (Figure 3). Both sets are numbered west to east. The NS Faults have an average thickness of $0.3 \mathrm{~m}$ with an infill of rubble and graphite. NNW faults have an average thickness of $0.8 \mathrm{~m}$ with an infill of talc, rubble and dolomite. Relict bedding is also present dipping approximately $60^{\circ}$ to the west (Chitumbura et al. 2014).

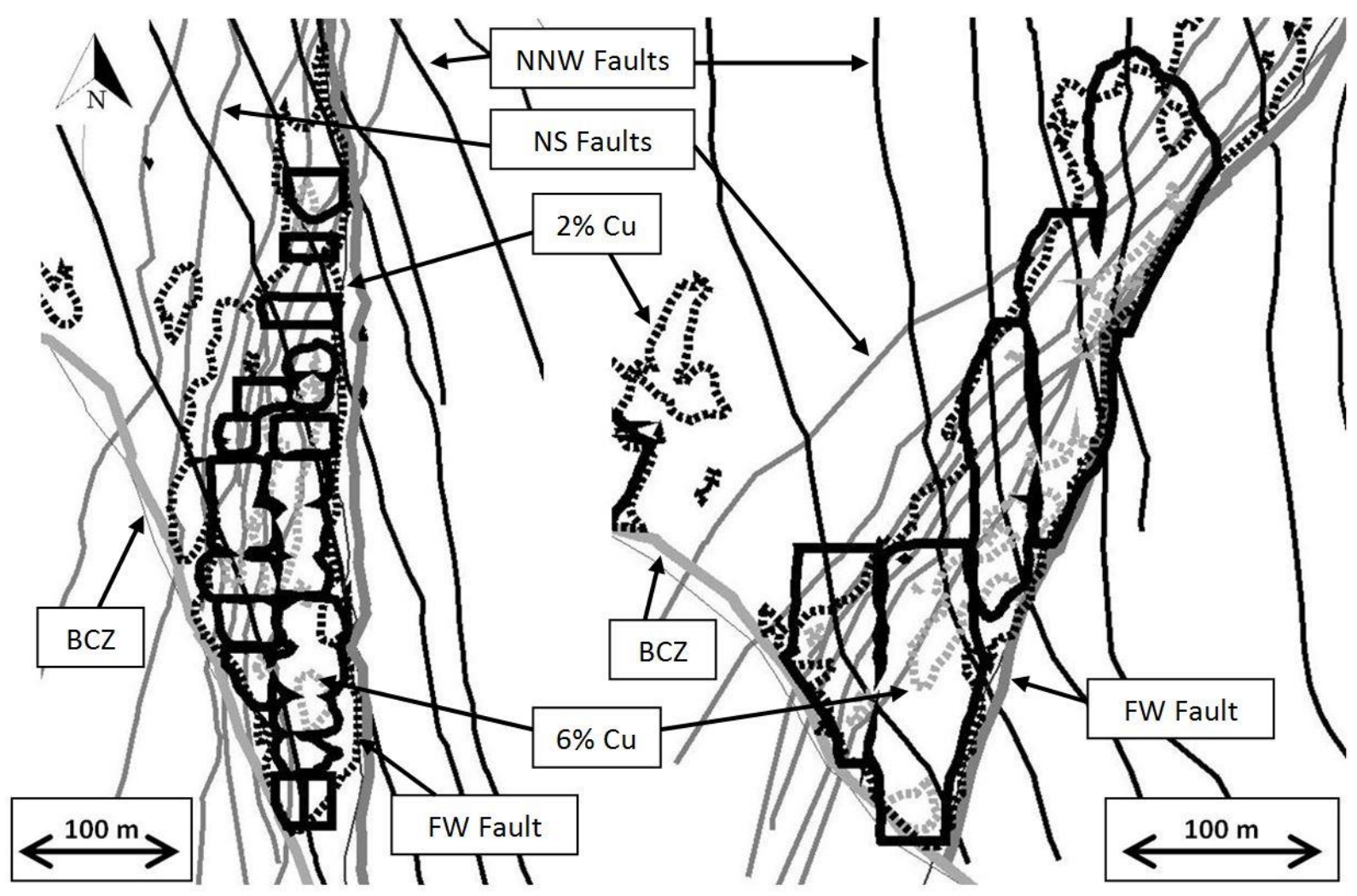

Figure 33500 Orebody in plan on 28D (2005 RL) (left) and section looking north (right) 


\subsubsection{Stress regime}

A number of stress measurements have been taken in the area of the orebody (MIM 2014). Table 2 shows the stress regime currently used in Map3D numerical modelling of the orebody.

Table 23500 Orebody stress regime (MIM 2014)

\begin{tabular}{ccccc}
\hline Stress & Orientation & $\begin{array}{c}\text { Magnitude } \\
(\mathbf{M P a})\end{array}$ & $\begin{array}{c}\text { Trend } \\
\left.\mathbf{(}^{\circ}\right)\end{array}$ & $\begin{array}{c}\text { Plunge } \\
\left.\mathbf{(}^{\circ}\right)\end{array}$ \\
\hline$\sigma_{1}$ & North-south & 44.8 & 176 & 4.8 \\
$\sigma_{2}$ & Vertical & 32 & 281 & 70.9 \\
$\sigma_{3}$ & East-west & 29.3 & 84.8 & 18.4 \\
\hline
\end{tabular}

Trend is measured clockwise from north at $0^{\circ}$. Plunge is measured clockwise from the horizontal at $0^{\circ}$.

\subsubsection{Stope performance}

Seventy-four stopes have been extracted to date in the 3500 Orebody. At least one stope is in production at any time with another being filled and a number being developed and designed.

Stopes are designed by a multi-disciplinary team with feedback from operational departments. A typical geotechnical process is shown in Figure 4.

Block Note

General Rock Mechanics issues addressed for a group of stopes describing the geotechnical environment. It will ensure that Major issues are eliminated.

Some rough analysis is done with prelim shapes (Size, sequence etc.)<smiles>CCCCC</smiles>

Reconciliation

After the stope is produced a stope reconciliation meeting is held where the performance of the stope is discussed in a presentation format. The key geotechnical issues addressed at this meeting is the actual vs. predicted performance of the stope and the key learning's that must be applied to future stopes in the area

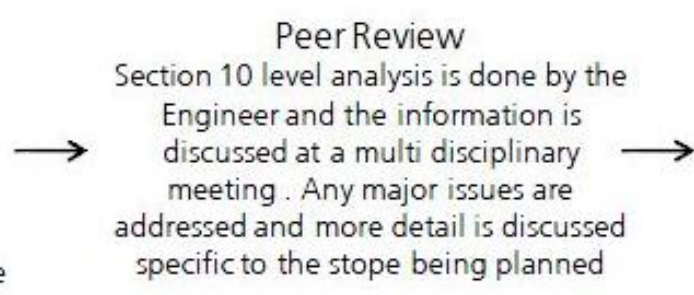

Peer Review ection 10 level analysis is done by the Engineer and the information is discussed at a multi disciplinary ddressed and more detail is discussed specific to the stope being planned

Stope Note

All geotechnical issues are addressed in this document. Please refer to GLD - 450314 for more information regarding the content.

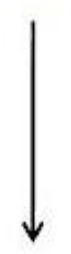

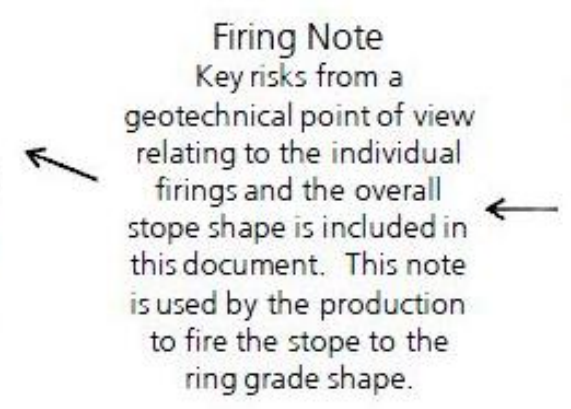

Firing Note Key risks from a geotechnical point of view firings and the overall stope shape is included in this document. This note used by the production ring grade shape.
Final Design

Key risks from a geotechnical point of view is included with the remedial actions in the Final design document. The Final Design includes information from the different stake holders (Planning, Geology, Ventilation and Rock Mechanics)

Figure 4 The geotechnical stope design process (MIM 2014)

Overbreak in 3500 Orebody stopes has usually occurred where faults run parallel in close proximity to stope surfaces. In particular stope surfaces close to the FW Fault will often overbreak to the structure due to its high talc content and sheared rock mass conditions. Large stope spans and delayed filling has also caused overbreak (MIM 2014). U657 stope was designed to produce $94,736 \mathrm{t}$; due predominantly to delays in filling but with a number of other contributing factors the final void of U657 stope was $148,494 \mathrm{t}$, overbreak of $53,758 \mathrm{t}$ or $56 \%$ of the design. Overbreak can lead to oversize rocks reporting to drawpoints and therefore slow extraction rates, dilution and disruptions to the mine schedule. If mullock is left at the base of the stope ore can be sterilised within pillars left to enable extraction of the next stope in the sequence. 


\subsubsection{U64 stoping block situation}

U642, U650 and U654 stopes are mullock-filled stopes in the north western part of the 3500 Orebody extracted between 2005 and 2007. In early 2010, the design process started for the stopes to the west of these stopes starting with U643 and including U644, U646, U651 and U653 (Figure 5). While U645 (2008) and U647 (2005) stopes had been extracted adjacent to these fill masses the greater height of U643 was assessed to leave a pillar too slender to be stable. Failure of the pillar would risk the safety of mine personnel, risk the stability of vital infrastructure on higher levels and would sterilise more ore. It was felt that thickening the pillar to a thickness assessed likely to remain stable would sterilise an unacceptable amount of ore and following a risk assessment into the stability of the pillar U643 was divided into two lifts (Allnutt 2010).

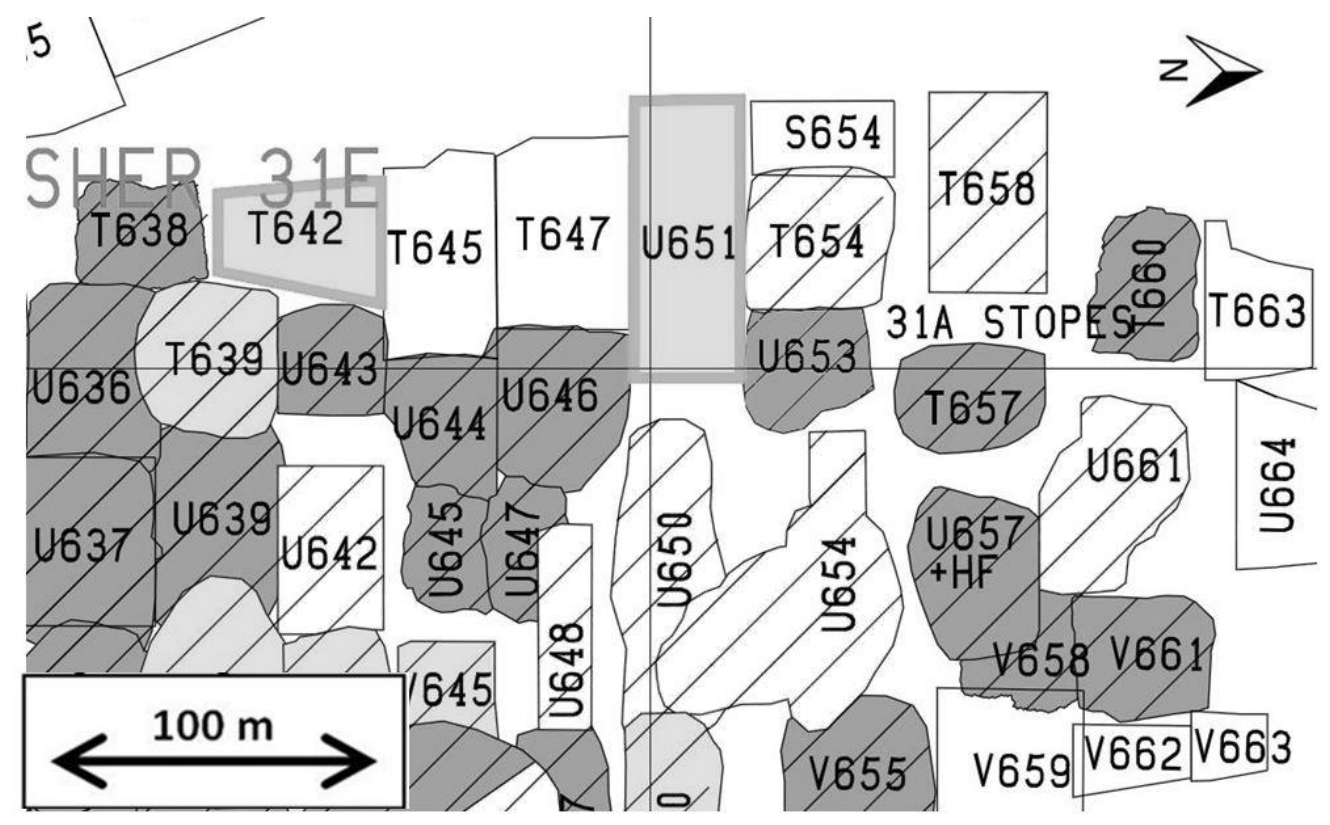

Figure 5 U64 area. Dark grey stopes are paste filled, light grey are CHF filled and white hatched stopes are mullock-filled. Plain white stopes are future stopes. T642 and U651 are being paste filled at the time of writing. T654 is filled with CHF around a mullock core

\section{$3 \quad$ Two-lift stoping}

\subsection{Planned method - U643}

U643 Lift 1 was designed to be $81,206 \mathrm{t}$ at $6.19 \% \mathrm{Cu}$. It had drawpoints on 30E (1890 RL) and was drilled from $29 \mathrm{E}$ (1950 RL), a vertical height of $63 \mathrm{~m}$. Lift 2 was 76,230 t at 3.52\% copper with drawpoints on $29 \mathrm{E}$ and drilling from 28D (2005 RL), a vertical height of $58 \mathrm{~m}$ (Ireland 2010a).

For both levels, the cutoff was located to the south of the stope and retreated to the north, exposing the pillar with U642 to the east gradually (Figure 6). A 15 m pillar was left with U642 until the end of the lift when a scavenger ring was fired with lower strength explosives, taking the pillar to $11 \mathrm{~m}$ (Waters 2010). The north-south dimension of the pillar was $35 \mathrm{~m}$. Drilling for Lift 2 was undertaken while Lift 1 was mucking (Ireland 2010a). This had the added benefit that drill hole break throughs could be checked to verify drill hole orientation.

Pillar stability assessment was undertaken by numerical modelling, a qualitative assessment of the rock mass and by comparison with the pillars which had been left for U645 and U647 with the adjoining mullock fill masses. As no Optech had been taken of the base of U642, probe drilling was undertaken to verify the position of the western wall of $\mathrm{U} 642$ during drilling of the production drill holes. The installation of pillar cables was also investigated but was thought unlikely to be effective (Waters 2010). 
Monitoring of the pillar during extraction was to be by regular Optechs (cavity monitoring system) as no instrumentation could be installed in the pillar with the correct orientation (Waters 2010).

A risk assessment for driving a loader on $\mathrm{U} 643$ paste fill mass was also conducted, as this had not been done at the mine for some time (Ireland 2010b). The controls were a slightly increased cement content in the paste fill (4\% instead of $3 \%$ ), that the loader was to be in line of sight remote operation when on the fill and that broken material was to be left on top of the fill to provide a firmer floor (Ireland 2010b).

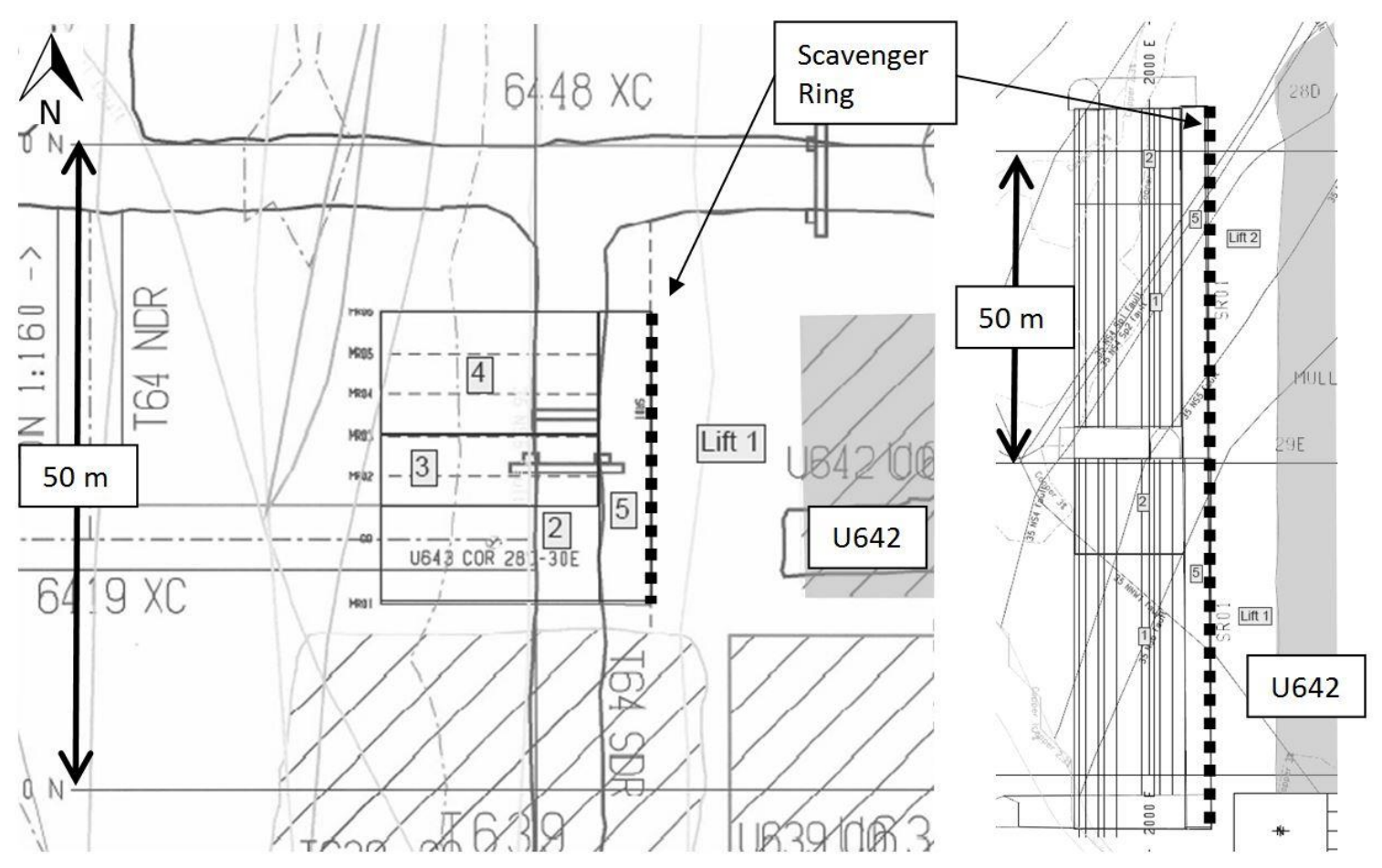

Figure 6 U643 29E level firing sequence (left) and section looking north showing cutoff drill patterns (right). Major structures are shown in grey (Ireland 2010a)

Extraction of the first lift of U643 proceeded without incident and the first lift was paste filled. While standard drawpoint support (split sets, mesh and $6 \mathrm{~m}$ cable bolts) had been installed during development and rehab for stope access on 29E in 6448 XC and 6419 XC (Figure 6) minor additional support was required in the northern access off $6448 \mathrm{XC}$ after the filling of the first lift. This delayed the firing of the second lift by a few days. The additional support consisted of $75 \mathrm{~mm}$ poly fibre reinforced shotcrete in the drawpoint and sidewall cables in the southern wall of $6448 \mathrm{XC}$ as the rock mass was showing signs of relaxation (Ireland et al. 2010).

Lift 2 extraction then commenced and on completion the remainder of the stope was paste filled. In total $175,970 \mathrm{t}$ was extracted from the stope at $4.95 \%$ copper, compared to the design tonnes of $157,436 \mathrm{t}$. The overbreak of 18,534 $\mathrm{t}$ (11.8\% of design) occurred predominantly from the crown and western wall of Lift 2 and was attributed to fault interactions. Less than $1 \mathrm{~m}$ of fall-off occurred from the eastern wall.

\subsection{Adjustments to method - U644 and U646}

U644 was located to the north of U643, forming an ' $L$ ' shape to the northwest of U642 (Figure 7). After the success of U643 extraction it was also taken as two lifts, but with a slightly taller Lift 2, with drilling from 27C (2055 RL), but the stope was not fired through to the level (Ozen 2011). A pillar of at least $10 \mathrm{~m}$ was again designed with U642 and probe drilled (Ozen 2011). Lift 1 was $60 \mathrm{~m}$ vertical height and Lift 2 was $76 \mathrm{~m}$, the east west length was $20 \mathrm{~m}$. The stope was produced in late 2011 to early 2012 . The total design shape for the stope was $179,602 \mathrm{t}$ and $178,419 \mathrm{t}$ were extracted, an underbreak of $1,183 \mathrm{t}$ or $0.65 \%$ of the designed shape. Pillar stability assessment was again by numerical modelling and based on the U643/U642 
pillars (Matthews 2011). Drawpoint support on 29E for the second lift (6 m cable bolts) was delayed until Lift 1 had been filled to avoid having to re-install the support as had happened with U643 (Ozen et al. 2012).

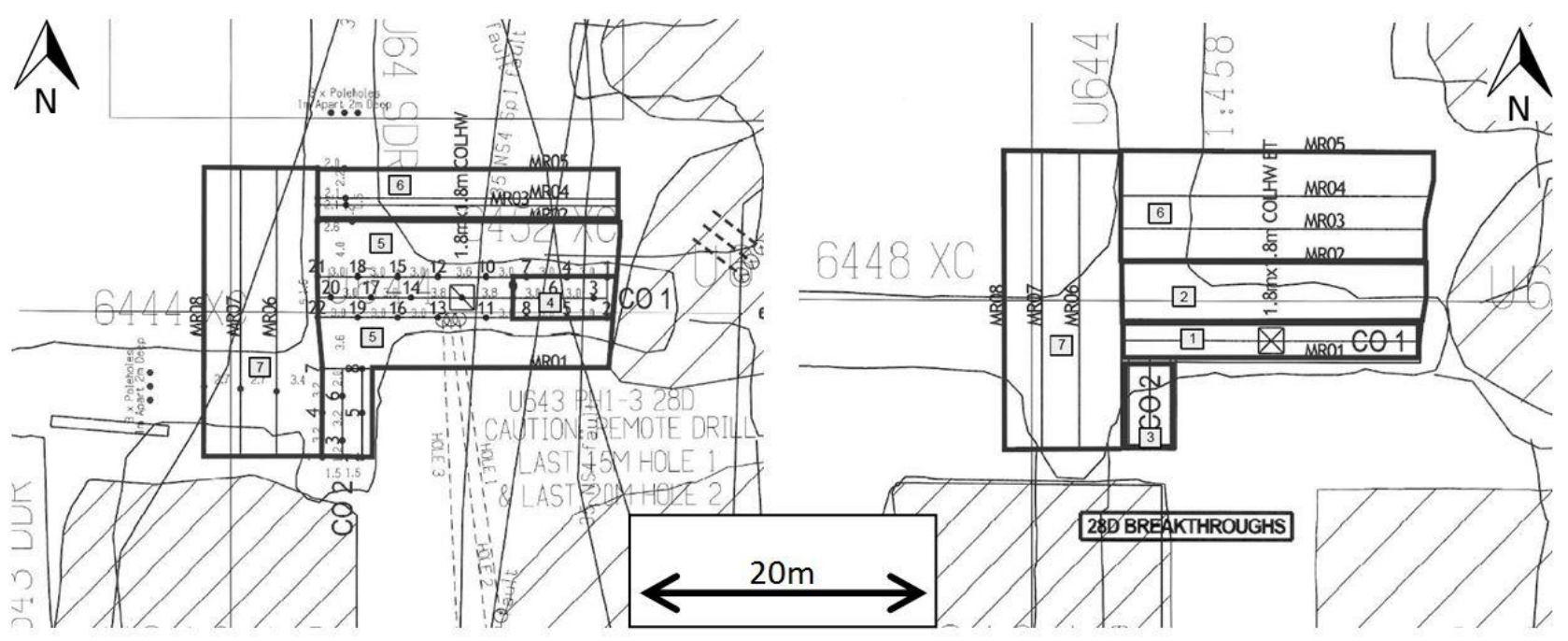

Figure 7 U644 Lift 2 level firing sequence on 28D (left) and 29E (right) (Ozen 2011)

Although the stope underbroke overall overbreak from the pillar with U642 was revealed with the final Optechs for Lift 2 reducing the final pillar width to $7 \mathrm{~m}$ (Figure 8). The overbreak was thought to be due to the sharp internal angle 'rounding off'. Stope filling was expedited to limit further fall-off.

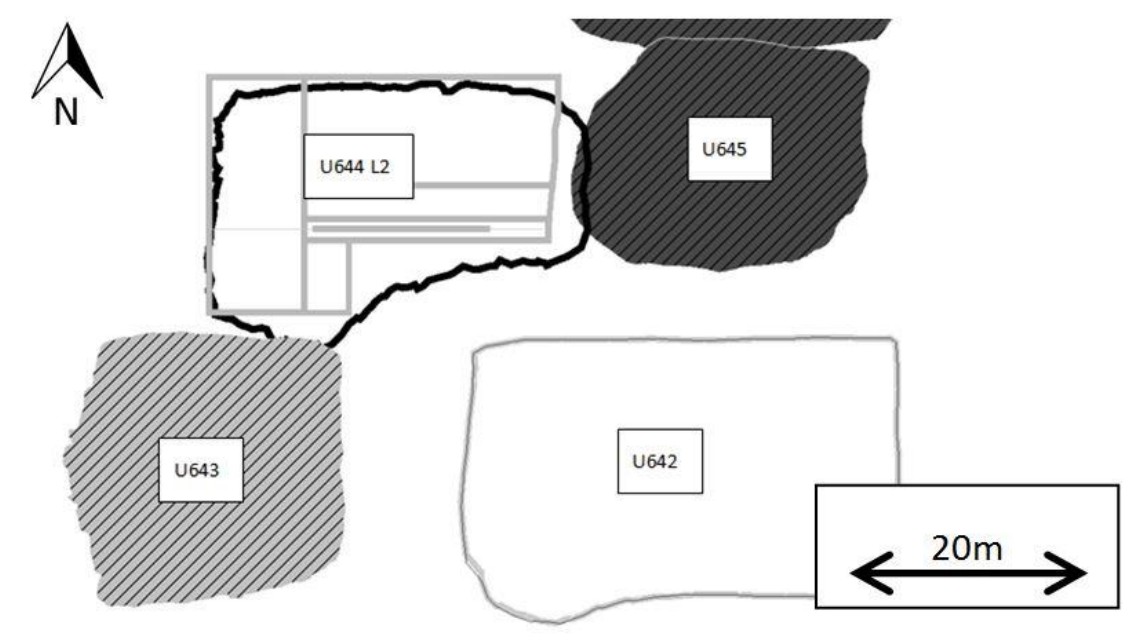

Figure 8 U644 Lift 2 level firing sequence on 28B with design shape in grey and Optech in black

U646 was extended deeper down to 30A (1850 RL). Lift 1 was $55 \mathrm{~m}$ in vertical height and Lift 2 as $57 \mathrm{~m}$, with an east-west length of $18 \mathrm{~m}$. To provide a stable drawpoint on 30A an extension on the northern side of the stope was required (Figure 9); however, this undercut the $10 \mathrm{~m}$ pillar with $\mathrm{U} 650$ and was predicted to adversely affect the stability of the pillar and the rock mechanics stope note recommended that the extension was not extracted (Matthews 2012). U646 Lift 1 began production in October 2012, but production was halted early in May 2013 when Optechs showed that stope was close to breaching the U650 mullock fill mass (Lynn et al. 2013). While the position of the U650 void was not known with certainty as no Optech had been taken of the stope, the stope design shape was used and probe drilling had been undertaken to prove that a sufficient pillar was present. However, the holes had not been drilled to breakthrough so the stope design shape was used as the actual shape. This led to a loss in extracted tonnes from the first lift as muck was left in the base of the stope (Lynn et al. 2013). The overbreak was attributed 
to the undercutting of the pillar by the northern extension and rounding off of the sharp angles, as had been seen in U644 Lift 2.

Lift 2, which did not have an extension to the north was produced between July and October 2013 with no major issues. The stope was drilled after Lift 1 had been filled and cured due to drill rig availability. Minor rehab was required to the Lift 2 drawpoints due to corrosion of the ground support as a result of the humid conditions caused by the filling of Lift 1, possibly exacerbated by drill water (Buchanan 2013).

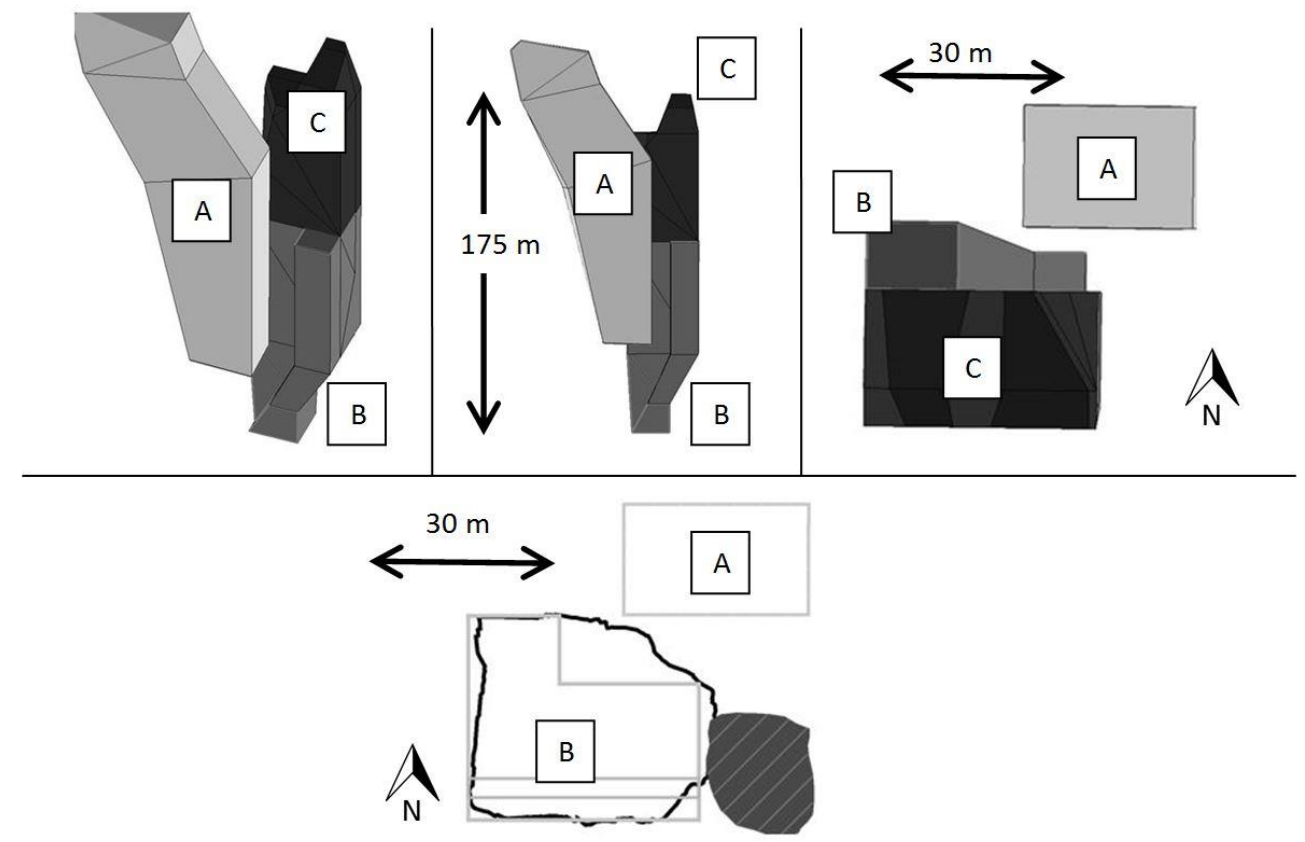

Figure 9 Top row: U650 (A, light grey, U646 Lift 1 (B, dark grey) and U646 Lift 2 (C, black) looking SE (left), looking south (centre) and in plan (right). Bottom row: section through Lift 1 on 29A showing U646 design shape (light grey) and Optech (black)

\subsection{Evaluation of two-lift stoping}

The adoption of a two-lift stoping technique has enabled the extraction of three stopes which may not have been extracted otherwise due to concerns about pillar stability, or which would have been extracted with drastically reduced sizes to allow larger pillars to be left. A total of 763,944t was extracted in the three stopes which, along with U653 which was extracted at the same time as U644 and U651 which is currently in production will provide a 'wall' of cemented fill around the mullock-filled stopes thereby allowing the next retreat to the west to be extracted without having to leave pillars.

While two-lift stoping is an effective method in leaving as little ore behind as possible it does take longer than taking a single lift stope. It also entails more drilling and incurs additional ground support costs, both in developing the stope and rehabilitation after the first lift has been taken.

Other methods used to increase pillar stability in the mine include orientating cutoff slots and main rings perpendicularly to the pillar so that the full pillar is only exposed after the final stope firing, limiting the required stand up time. However, this method does mean that the main rings toe into the pillar which may also weaken it. A possible solution to this is the scavenger ring as utilised for U643; however, development geometry often means it is not possible to drill such a ring. If main rings are orientated parallel to the pillar low strength explosives are used in the adjacent ring to limit blast damage.

\section{$4 \quad$ Pillar ratios}

As a result of the instability of the U646 Lift 1 pillar with $U 650$ and other recent pillar failures, more quantitative methods to assess pillar stability in the northern 3500 orebody were investigated. As detailed 
below empirical graphs had been investigated in the past but as they had been used incorrectly were not felt to be relevant to the orebody and stoping method; pillars which were known to have remained stable would have been predicted to fail using the graphs. A more site specific method was required. One of the methods assessed was to compare the pillar vertical height to thickness ratio of stopes in the area. Initially used as a 'rough guide' method by the area rock mechanics engineer as more examples became available supporting the effectiveness of the method it has become another useful tool in designing pillars with mullock-filled stopes.

\subsection{Method}

Most pillar stability methods define pillar height as the pillar dimension parallel to the principal stress and pillar width as the smaller of the two other perpendicular dimensions and use a pillar width to height ratio. When this ratio with the standard definitions was used with the examples available a wide range of values resulted, showing no discernible trend (Figure 10).

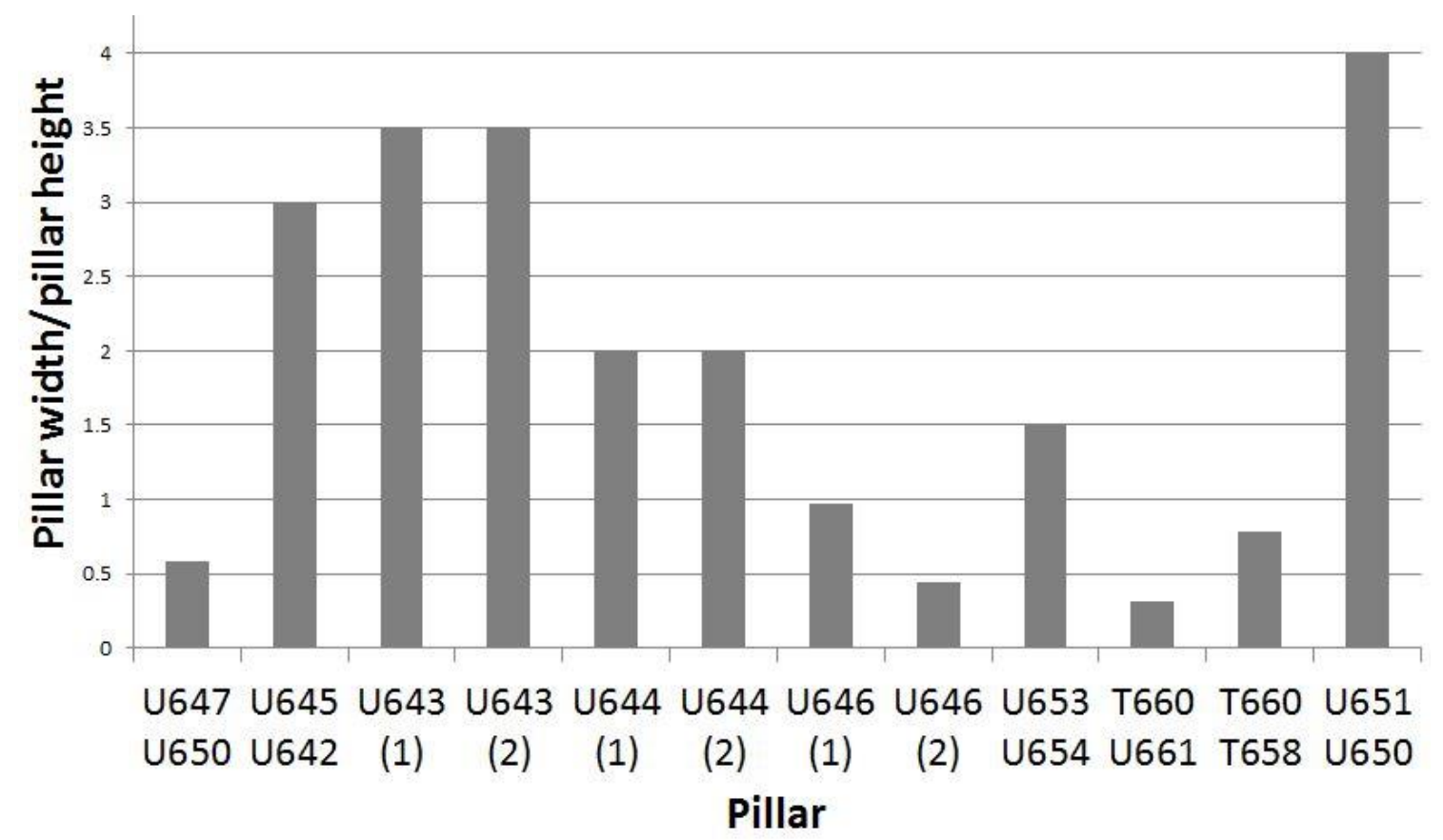

Figure 10 Graph showing pillar width to height ratios in the 3500 orebody

A pillar vertical height to thickness ratio was then trialled and has been used in the assessment below. Pillar thickness is the horizontal distance between the stope of interest and the mullock-filled stope. The ratio was reversed so that the results are above 1 to aid understanding by non-technical personnel.

\subsection{Stope examples}

The pillars with mullock-filled stopes from individual lifts of the three stopes described in Section 3, U643, U644 and U646 were measured along with U647 and U645 which had previously been extracted in the area. U653 was also included. It was extracted at the same time as U644 but as it was of a lesser height due to the grade in the area it was not necessary to extract it as two lifts. The pillars range between 10 and $20 \mathrm{~m}$ in thickness and 55 and $110 \mathrm{~m}$ in vertical height (Figure 11). All the pillars are vertical and of uniform thickness. 


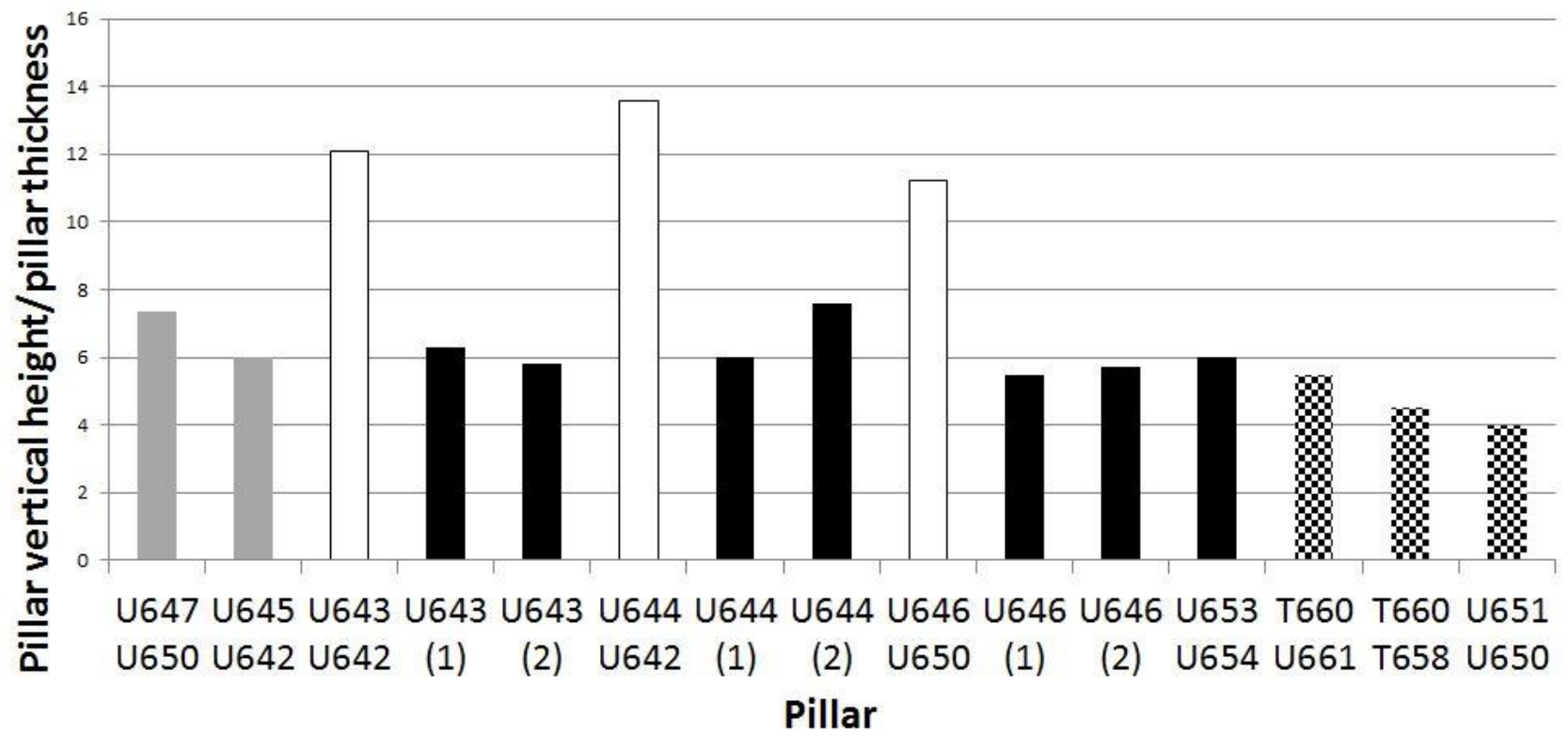

Figure 11 Graph showing pillar vertical height to thickness ratios in the 3500 orebody. Grey stopes were extracted before the two-lift stoping method was adopted. Black stopes are the two-lift stopes with U653; the results if the stopes were taken as one lift are shown in white. Stopes in which the pillar vertical height to thickness ratio method has been applied are checked

T660 stope was extracted in early 2014 and had pillars with two mullock-filled stopes: U661 to the east and T658 to the south. Pillar stability analysis was undertaken by numerical modelling and the Lunder and Pakalnis (1997) pillar stability graph. The pillar with U661 was predicted to be unstable using these methods and support in the form of sidewall cables was installed.

U651 production started in October 2014 and is currently being filled. It has a pillar with the mullock-filled U650 to the east. During the design stage of the stope, a number of alternative shapes were investigated and the pillar stability assessed, as shown in Table 3 and Figure 12.

Table 3 U651 pillar ratios for design options

\begin{tabular}{lccc}
\hline Design option & $\begin{array}{c}\text { Pillar vertical } \\
\text { height }(\mathbf{m})\end{array}$ & $\begin{array}{c}\text { Pillar thickness } \\
(\mathbf{m})\end{array}$ & Ratio \\
\hline U651 one lift & 117 & 10 & 11.7 \\
U651 two lift, Lift 1 & 57 & 10 & 5.7 \\
U651 two lift, Lift 2 & 60 & 10 & 6 \\
Short U651 & 97 & 10 & 9.7 \\
Thick pillar, U651 one lift & 117 & 15 & 7.8 \\
Thick pillar, short U651 & 97 & 15 & 6.5 \\
Final U651 & 60 & 15 & 4 \\
\hline
\end{tabular}

While the slightly shorter, thickened pillar option appeared the best from a geotechnical viewpoint the final U651 shape adopted was based on development and schedule constraints which saw U651 being combined with T651 to the west. 


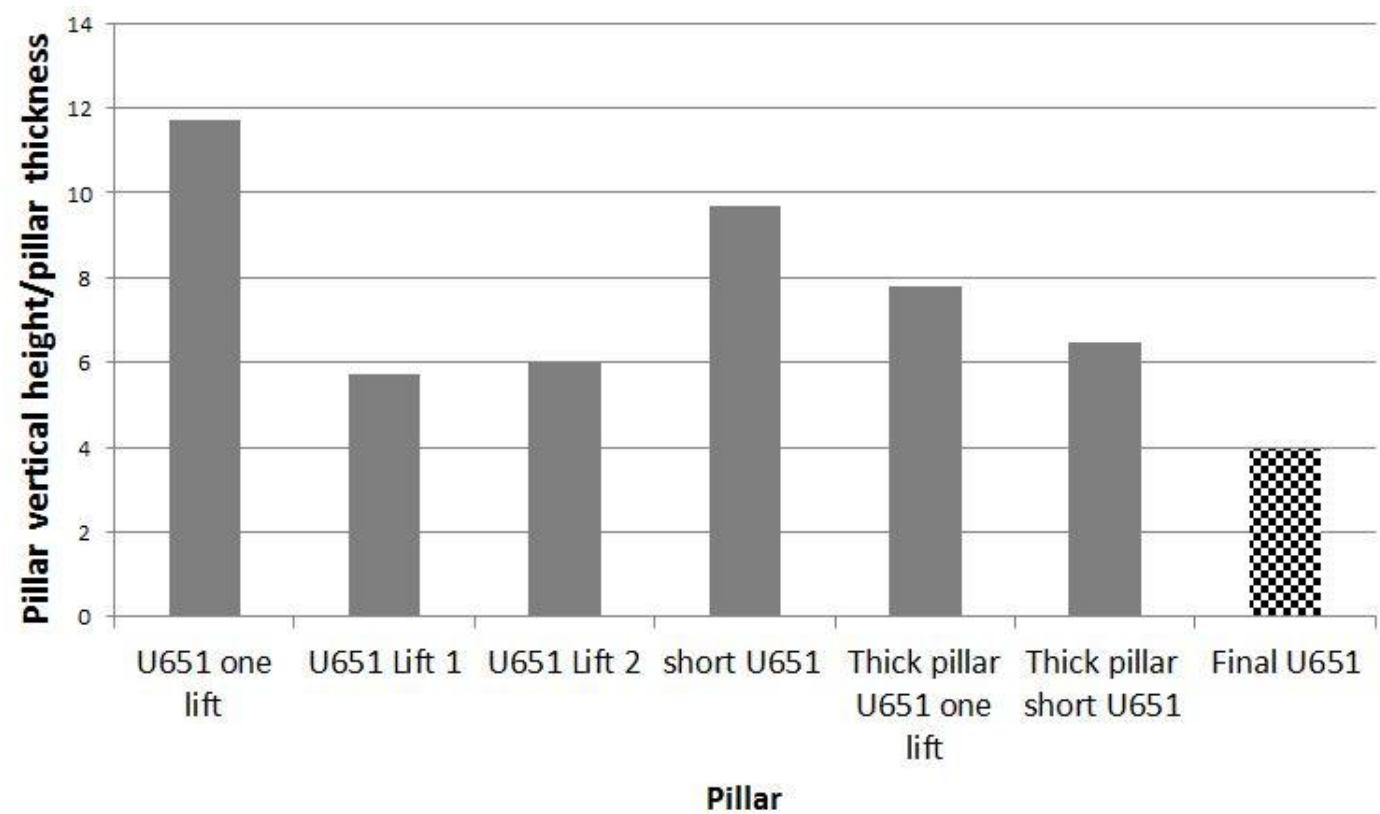

Figure 12 Graph showing pillar vertical height to thickness ratios for the various U651 shapes in Table 3. Actual pillar size adopted is shown checked

\subsection{Application in $\mathbf{3 5 0 0}$ Orebody}

The Lower $\mathrm{V}$ Block is a proposed block of three stopes situated below the 3500 Orebody. The block consists of three stopes with a total of $317 \mathrm{Kt}$ at $2 \% \mathrm{Cu}$ (Matthews 2015a). The stability of the crown pillars with stopes above have been assessed by the Scaled Crown Pillar method as described by Chitumbura et al. (2014) and the Lunder and Pakalnis (1997) pillar stability graph. There are three pillars in the block with existing mullock-filled stopes adjacent and one pillar between two of the planned stopes (Figure 13). Using a pillar height to width ratio of six as indicating that the pillar is predicted to remain stable (taken from Figure 11), then the pillars between the planned V657 and U658 with U661 would be predicted to remain stable, as would the pillar between the planned U655 and U646, which has mullock remaining in the base of the stope (Section 3.2).

The pillar between the planned U657 and V657 was predicted to be unstable. As U658 would undercut the V657 fill mass it was recommended that the pillar be re-designed so that the sidewall of V657 was vertical and could be exposed in U658 (Matthews 2015a).

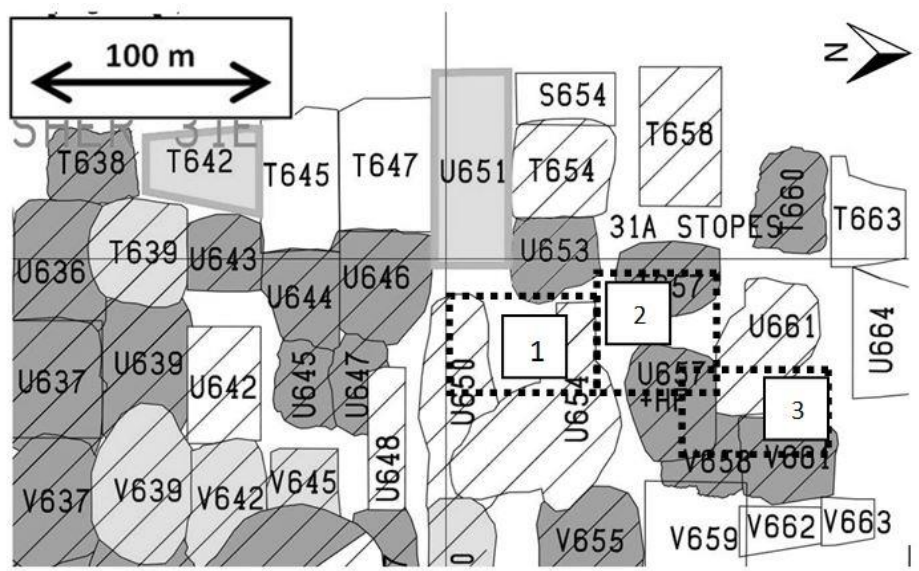

(a)

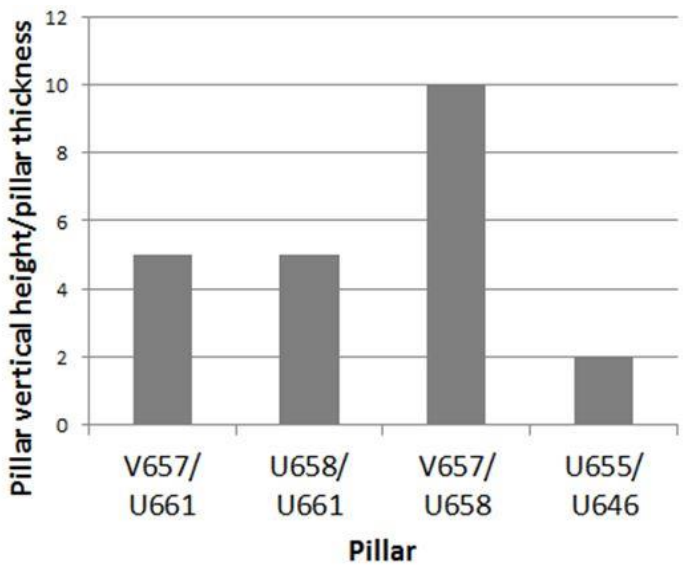

(b)

Figure 13 (a) position of Lower V Block stopes (dashed lines) U655 (1), V657 (2) and U658 (3); (b) graph showing pillar vertical height to thickness ratios for the Lower $V$ Block 


\subsection{Comparison with other methods}

As previously stated, the Lunder and Pakalnis (1997) pillar stability graph was not used in the Enterprise mine to assess pillar stability as the pillars under assessment did not plot on the graph. However, this was found to be an error in the use of the graph where pillar height is parallel to the primary stress direction in the pillar, not the vertical height. Figure 14 illustrates that of the 12 pillars shown in Figure 11, which are known to have been stable, 7 plot in the failed zone of the graph, 2 plot in the unstable zone and 3 plot in the stable zone.

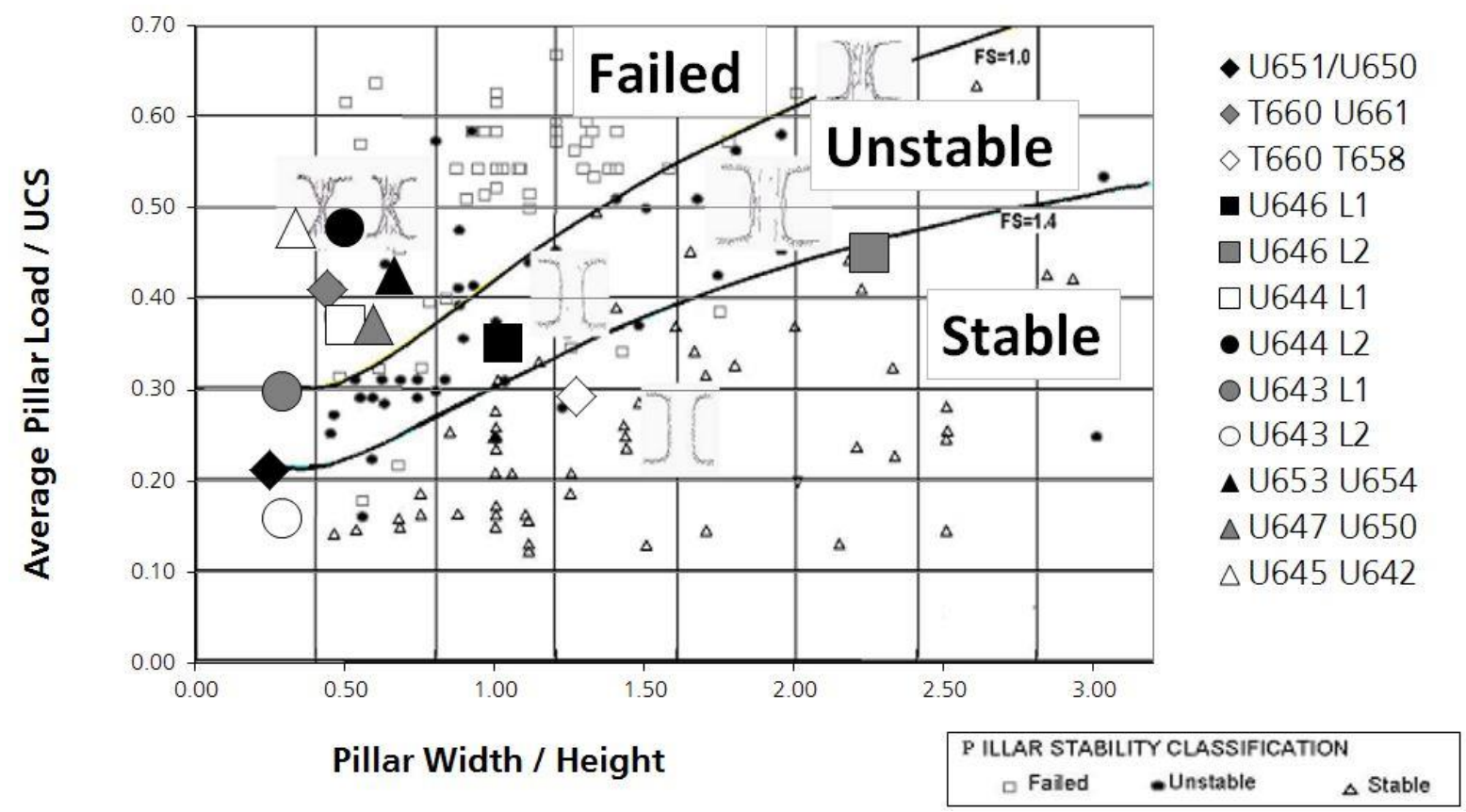

Figure 14 Pillar Stability graph for 3500 pillars with mullock-filled stopes (after Lunder \& Pakalnis 1997). Compare with Figure 10

When the pillar stability method is used for the Lower V Block stopes the V657/U658 pillar is predicted to fail and the V657/U661 pillar is predicted to be stable as they are with the pillar ratio method. However, the U655/U646 and U658/U661 pillars which were predicted to be stable using the pillar ratio method plot in the failed zone of the pillar stability graph (Figure 15).

Due to the conflicting results, it was recommended that a number of measures commonly used to improve pillar stability as detailed in Section 3.3 be implemented. It was also recommended that rock mechanics monitoring instrumentation be installed so that if failure did occur, or look imminent then control measures can be implemented, such as halting production and filling the stope (Matthews 2015a). Back-analysis after the extraction of the first stope will also be undertaken to further refine the pillar design for the later stopes. 


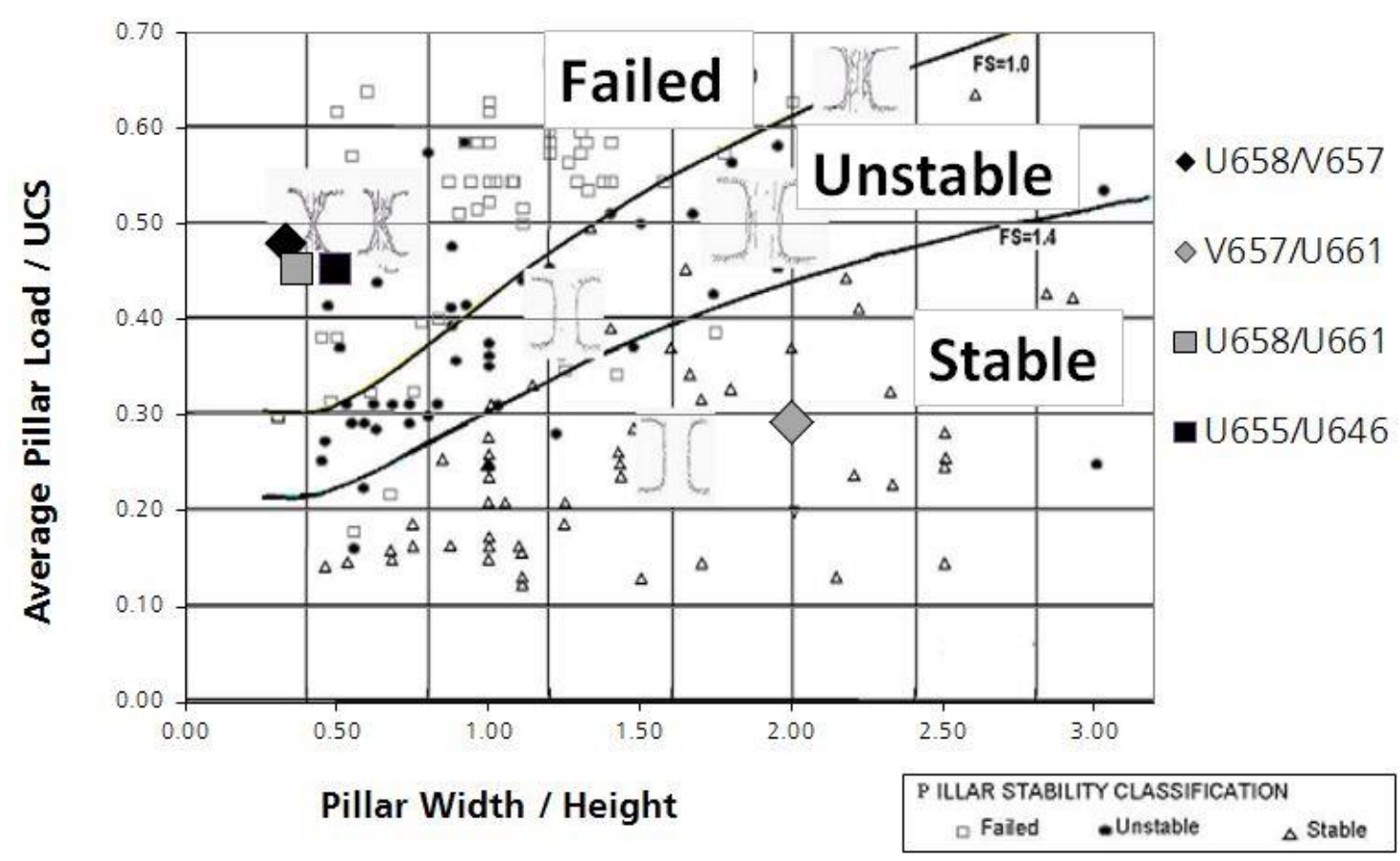

Figure 15 Pillar Stability graph for Lower V Block pillars (after Lunder \& Pakalnis 1997). Compare with Figure 13

It is thought that the reason for the limited effectiveness of the pillar stability graph and most other pillar stability assessment methods to pillars in the 3500 Orebody is due to the dimensions of the pillars. The stoping method used in the orebody is designed to backfill the stopes with cemented fills which can be exposed by the next stope in the sequence without leaving a pillar and sterilising ore. When pillars have to be left due to stope failure, they are extremely slender in comparison with the pillars on which the empirical methods are based, which are usually taken from board and pillar operations. In situations where pillars are required to support the surrounding rock mass for longer than for the few months they will be exposed in the 3500 Orebody before the stope is backfilled.

The uniaxial compressive strength (UCS) and pillar load inputs used in Figures 14 and 15 are also likely to be unrepresentative of the actual values. UCS was used in the calculation of the values used in the graph; however, as all the pillars studied have at least one major structure intersecting them, the strength of the rock mass in the pillar is likely to be much less than the strength of the rock itself within the pillar as represented by the UCS strength. This is also likely to be exacerbated by damage to the rock mass caused by the extraction of the adjacent stope. However this would mean the pillars would plot as being more stable than they are, not less as shown.

The pillar examples are plotting as less stable than they appear to be in reality and this is therefore thought to be due to an overestimation of the stresses acting on the pillars. An obvious reason for this is mistakes in numerical modelling due to wrong input parameters being used, however errors may also occur as the stress regime around the pillars are very complex and only elastic modelling is used during stope design. While back-analysis is undertaken, the pillars cannot usually be inspected due to the stoping method used. While Optechs are taken at the end of stope production, rill piles of failed fill or barren rock are often left at the far side of stopes, usually against pillars restricting the view of the pillars. Therefore, the usual signs that a pillar is taking stress as listed by Potvin et al. (1989) including cracking and spalling of the pillar or hour-glassing cannot be observed. It may also be that the pillars are no longer carrying stress, either because the stresses have been diverted around the pillar or that it has in fact failed. The pillars plotted above may still retain integrity although they are not transmitting stress; due to the lack of access, failure would only usually be noticed by ingress of mullock into the active stope. The small amount of confinement 
provided by the mullock fill is also discounted in the current numerical modelling as extracted stopes are usually modelled as voids.

\subsection{Other applications}

The pillar thickness ratio method was also recently applied to the southern 3000 Orebody for T608 stope design (Matthews 2015b). T608 will be located between two mullock-filled stopes, T602 to the south and S610 to the north. As T602 stope angles towards T608 design shape the pillar is 20 m thick at the base and $5 \mathrm{~m}$ thick at its top while no pillar was designed with $\mathrm{S} 610$ a $10 \mathrm{~m}$ thick pillar was used in the analysis. The pillar between T608 and T602 will be $60 \mathrm{~m}$ in vertical height and the T608/S610 pillar $45 \mathrm{~m}$. As Figure 16 shows, the T608 pillars with T602 and S610 plot in the failed zone of the pillar stability graph.

Stopes in the area which had been extracted adjacent to mullock-filled stopes leaving a stable pillar were investigated, the pillar dimensions were measured and a stable vertical height to thickness ratio determined. As in the 3500 Orebody, a ratio of six was also determined in the area, possibly due to a similar rock mass.

While the top of the pillar with T602 would still be predicted to be likely to fail this was thought to be acceptable due to the geometry of the pillar. The base of the pillar and the $10 \mathrm{~m}$ pillar with $\$ 610$ would be predicted to remain stable (Matthews 2015b). A stope of 126,806 $\mathrm{t}$ at $1.7 \% \mathrm{Cu}$ has therefore been brought into the schedule when not thought possible before.

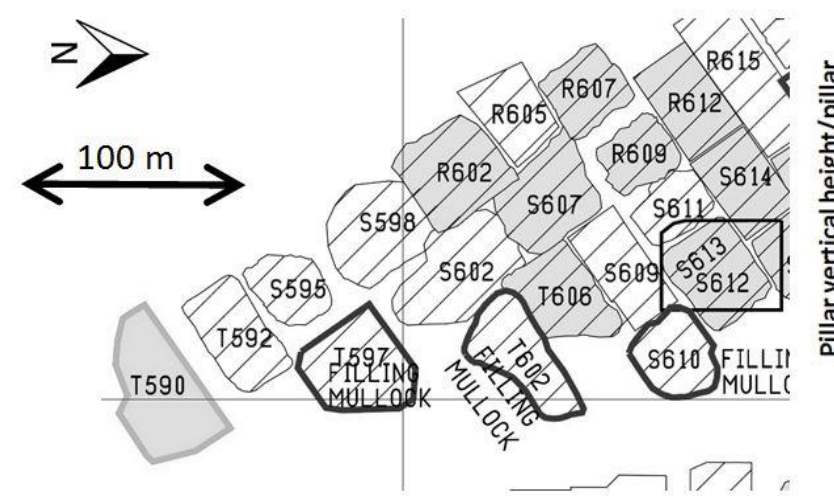

(a)

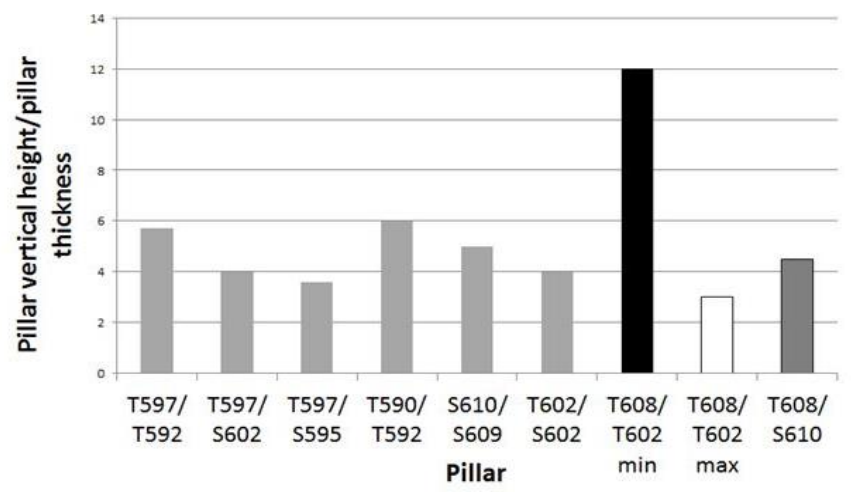

(b)

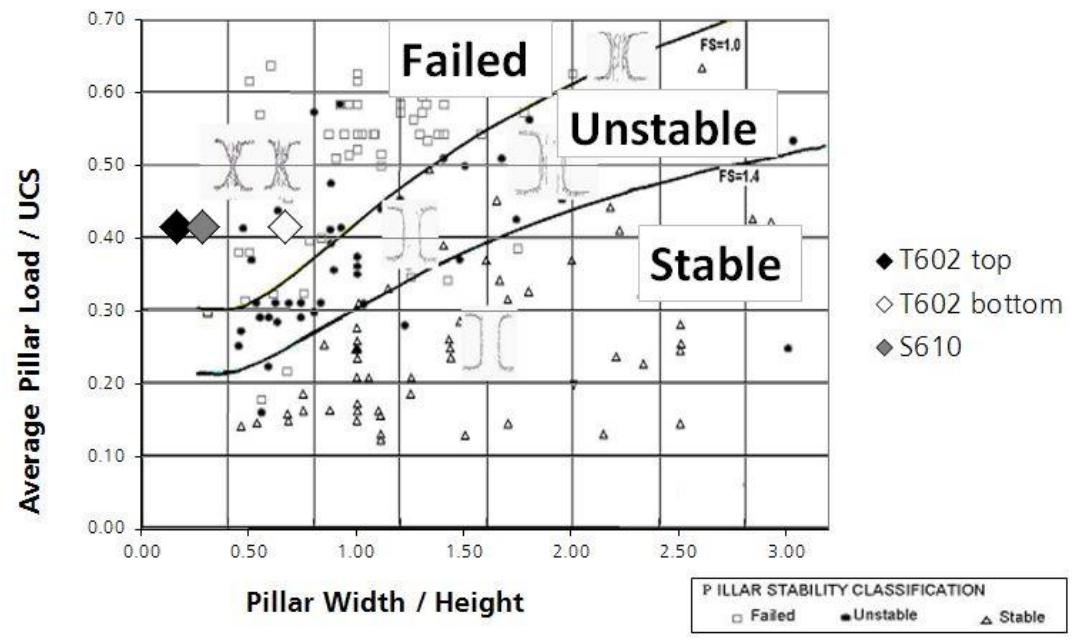

(c)

Figure 16 Pillar Stability assessments for T608 in the southern 3000 Orebody. (a) location. White hatched stopes are mullock-filled, and grey stopes are CHF filled; T590 is currently being filled with mullock. (b) pillar thickness ratio assessment. (c) pillar stability graph assessment (after Lunder \& Pakalnis 1997) 


\subsection{Evaluation}

The pillar vertical height to thickness ratio pillar stability assessment method has provided another tool to help assess pillar stability in an area where other methods have been proved to have limited effectiveness, or where sufficient accurate information is not available to implement them. It is a quantitative method, can be presented graphically and is area specific. It was initially used as a guide for rock mechanics when qualitative pillar stability methods were predominantly used or in the preliminary stages of an investigation.

Further refinements are possible, for example incorporating the data into a pillar stability graph as the data available already provides the horizontal axis. However, the cases available are still limited with fewer cases than other pillar stability assessment methods. Pillar failures would also be needed to plot a failure envelope.

The thickness ratio is very site specific as by ignoring the pillar strength and loading dimension it is assumed that the pillars have similar properties and loading conditions. While it is crude and takes no account of stress and rock strength, it is used in conjunction with other methods which do take these into account, but perhaps have less area specific effectiveness. The application of both empirical and numerical methods is recommended by others; Malan (2010) suggests an approach incorporating both empirical and numerical method, taking care that empirical methods are not extrapolated beyond the range of their source data and limiting the impact of flawed assumptions often used in numerical modelling.

\section{Conclusion}

The two-lift stoping method has allowed a significant amount of ore to be extracted adjacent to mullock-filled stopes with as little ore as possible becoming sterilised. During the design of the stopes, it became apparent that pillar stability assessment methods available to the area rock mechanics engineer were limited or ineffective, with methods showing pillars which were known to be stable should not be.

The two-lift stopes provided examples of stable pillars which were used in the pillar vertical height to thickness ratio method which has been successfully used elsewhere in the mine to justify the extraction of ore previously thought to have been sterilised.

\section{Acknowledgements}

The author thanks all those who have been involved in the design and planning of the 3500 Orebody, past present and future. Also those whose work into pillar stability assessment this paper is built on. Finally, thanks go to the management of Glencore's Mount Isa Mines for allowing the author to present this paper.

\section{References}

Allnutt, J 2010, Risk assessment report into the stability of the pillar between U643 and U642 during extraction of U642, internal publication, Mount Isa Mines.

Buchanan, A, Lynn, T \& Chase, A 2013, U646 L2 reconciliation, internal publication, Mount Isa Mines.

Burns, T 1993, 'A new mine project - the 3000 and 3500 Copper Orebodies at Mount Isa', Proceedings of the International Mining Geology Conference, Australian Institute of Mining and Metallurgy, Melbourne, pp. 87-96.

Chen, J 2002, Southern 3500 Orebody Review, Mount Isa Mines Ltd.

Chitumbura, G, Matthews, D, Ozen, I \& Jackson, S 2014, 'One mile underground - mining the N3500 Orebody at Mount Isa Mines', Proceedings of the 12th AUSIMM Underground Operators' Conference, Australian Institute of Mining and Metallurgy, Melbourne, pp. 267-283.

Ireland, A 2010a, U643 Stope Final Design Note, internal publication, Mount Isa Mines.

Ireland, A 2010b, Risk assessment report into driving loader on U643 paste fillmass 29E, internal publication, Mount Isa Mines.

Ireland, A, Bensley, A \& Matthews, D 2010, Primary development design \#2230 - Rehab of T64 SDR (U643 Lift 2 Drawpoint), internal publication, Mount Isa Mines.

Lunder, P \& Pakalnis, RC 1997, Determination of the strength of hard rock pillars, Bulletin of the Canadian Institute of Mining, Metallurgy and Petroleum, vol. 90, no. 1013, pp. 51-55.

Lynn, T, Bunker, K \& Buchanan, A 2013, U646 L1 reconciliation, internal publication, Mount Isa Mines. 
Malan, D 2010, 'Pillar design in hard rock mines - Can we do this with confidence', Proceedings of the Second Australasian Ground Control in Mining Conference, The Australasian Institute of Mining and Metallurgy, Melbourne, pp. 15-30.

Matthews, D 2011, U644 Rock Mechanics Stope Note, internal publication, Mount Isa Mines.

Matthews, D 2012, U646 Rock Mechanics Stope Note, internal publication, Mount Isa Mines.

Matthews, D 2015a, Lower V Block Preliminary Geotechnical review, internal publication, Mount Isa Mines.

Matthews, D 2015b, T608 Preliminary Geotechnical review, internal publication, Mount Isa Mines.

MIM 2014, Ground Control Management Plan, internal publication, Mount Isa Mines.

Ozen, I 2011, U644 Stope Final Design Note, internal publication, Mount Isa Mines.

Ozen, I, Coackley, H \& Matthews, D 2012, Primary Development Design \#2720 - Rehab of 6448 XC and U644 DDR, internal publication, Mount Isa Mines.

Potvin, Y, Hudyma, M \& Miller, H 1989, 'Rib pillar design in open stope mining', Bulletin of the Canadian Institute of Mining, Metallurgy and Petroleum, vol. 82, no. 927, pp. 31-36.

Waters, S 2010, U643 Rock Mechanics Stope Note, internal publication, Mount Isa Mines. 